\title{
The design and application of remote monitoring system on working condition of trap in steam pipe network
}

\author{
Wu Xiaolei ${ }^{1, a}$,Yu Xingjiang ${ }^{2, b}$, Ye Shengli ${ }^{3, c}$ and Xia Yunfei ${ }^{4, d}$ \\ China Tobacco Zhejiang Industrial Co.,Ltd, Hangzhou, China \\ awuxiaolei@zjtobacco.com
}

Keywords: trap; monitoring system

Abstract. the real-time remote monitoring shows the working status of trap in steam pipe network, and provides data for maintenance of trap in steam pipe network. based on the research of the steam trap's characteristics and working principle, the remote monitoring system of steam trap is built. The practical application shows that the system has realized the remote monitoring, achieving the goal of energy conservation and emissions reduction, and ensure the safety of pipeline equipment.

\section{Introduction}

Steam has been with locomotive and the industrial revolution for centuries, so far, and become an indispensable part of modern technique. Without steam, Industry Area such as food, textile, chemical, medicine, electricity, heating and other could not exist, neither develop as well as it is now.

The steam trap is a very important part In steam system. Steam trap is used in steam pipeline, steam heating equipment and heat pipe line, which can automatically remove steam condensate, air and other non condensable gases in equipment and piping, and is automatic valve which can prevent steam leakage. The pros and cons of steam trap's performance play the vital role in the operation of the steam system, the improvement of the thermal efficiency of steam equipment to and the rational use of energy, etc.

According to statistics report of bureau of energy heating system energy saving investigation of the national development and reform commission, at present the ownership of steam trap is about 4.324 million, about 80 percent of which are not follow the current national standard that steam leakage rate is less than $3 \%$, the most leakage rate is about $10 \%$. In the daily management of trap, the majority of enterprises in our country install the trap without management, and the lack of a simple and accurate detection method and late detection of breakdown of trap lead to a higher ratio of trap's harmful utilization.

The advanced remote monitoring technology can real-time monitoring the condition parameters and state of trap in steam pipe network and track abnormal data changes, and provide decision-making basis for maintenance, thereby improving the utilization rate of steam and scientific management level greatly.

\section{The process of drainage system}

The steam produced by the boiler is assigned to each steam-consumption unit, steam heating process has two ways: warm machine (tube) though steam and transfer heat to steam-consumption unit. when steam lost heat, it will turn into water, which is inevitable. Actually steam loses heat and became water once it leaves the boiler, and the condensed water flows in the bottom of the pipe.

The condensed water must be removed from the lowest point of steam system in time, because the heat exchange efficiency of condensed water is low, and the condensate water film lead to the decline in heat-transfer coefficient, and the air mixed into condensed water will cause corrosion damage of pipe equipment. At the same time, the accumulated condensate will make noise and cause destructive phenomenon- water hammer, as shown in figure 1.

Steam trap's duty is to eliminate condensation water and stop the steam escaping, and keep the steam as dry as possible before use, making utilization of steam effective and economic. 


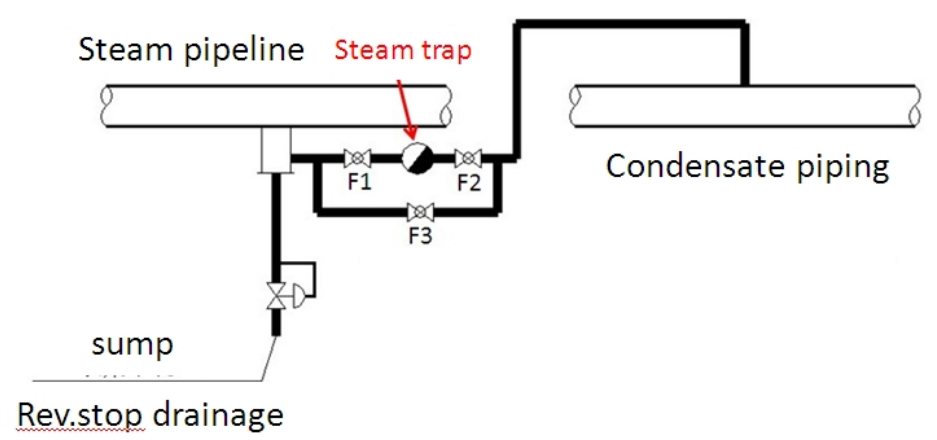

Figure 1 Steam trap flow diagram

The process of steam drain system in a cigarette factory in Hangzhou region is that the steam produced by boiler is sent to the distribution cylinders first, through which the steam is assigned to pipeline of steam-consumption unit, and the traps are installed on the distribution cylinders and pipe network of the steam system to drain water, as shown in figure 2.

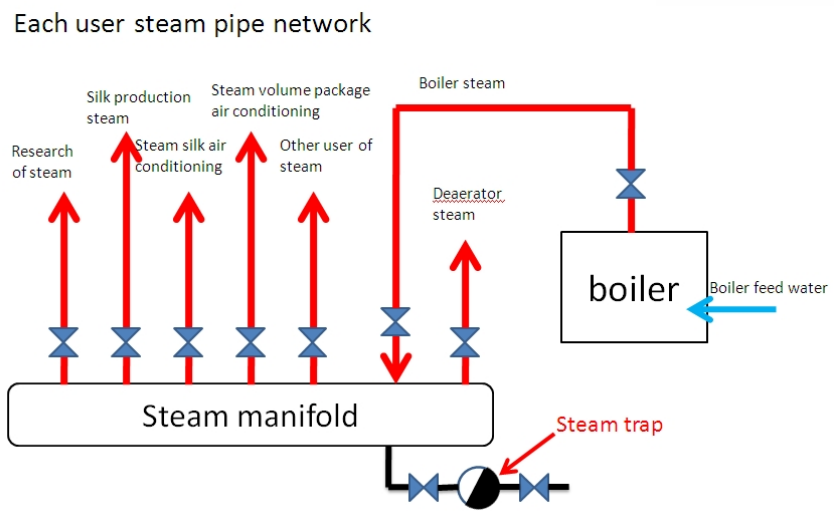

Figure 2 Steam supply flow diagram

A steam system (red triangle) has 12 groups of trap in total, distributed in seven areas in figure 3. The steam pipe network system consist of steam pipe for work and scientific research, steam pipe for tobacco primary processing, steam pipe for air conditioning used for tobacco volume package and other users of steam pipe system, this system has 24 traps, to provide steam for work, tobacco primary processing and tobacco volume package.

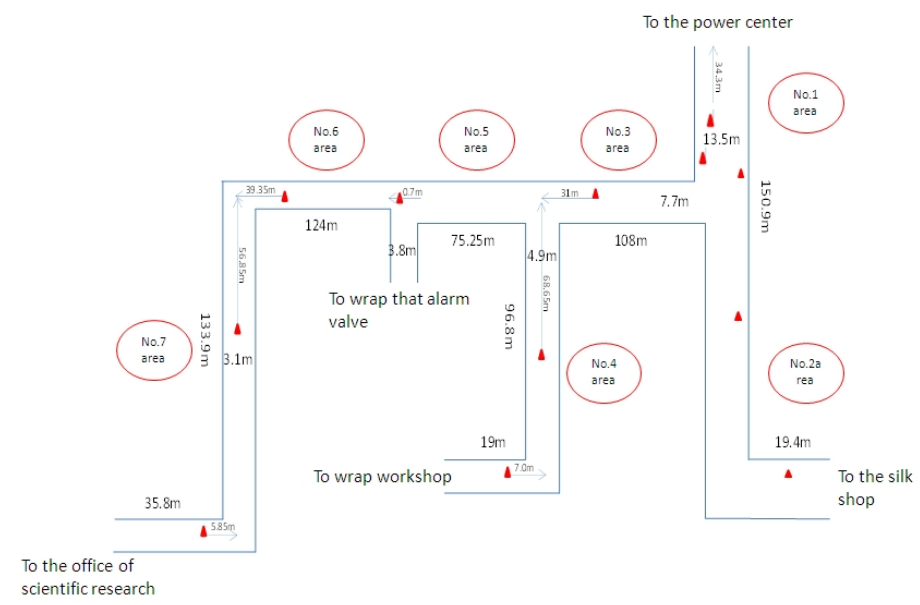

Figure 3 Steam system pipe network diagram

\section{Monitoring system construct scheme}

In order to accurately reflect the real working condition of trap, A monitoring system is built, and make it become more convenient for technicians to monitoring trap real-time and evaluate the performance and application effect performance of the steam-pipe network system, and provide data 
support for the follow-up maintenance. This system main monitoring the outlet temperature and vibration value of the steam trap, in order to obtain the real-time data of the trap's working condition. According to condition evaluation index of trap, the corresponding monitoring point of trap is set up, and the wireless-monitoring means adopted in monitoring scheme, and the host computer communicate with wireless equipment, through the gateway, to obtain trap's monitor information, realizing the online monitoring of system, providing data basis for the performance evaluation of the steam system in the future, as shown in figure 4.

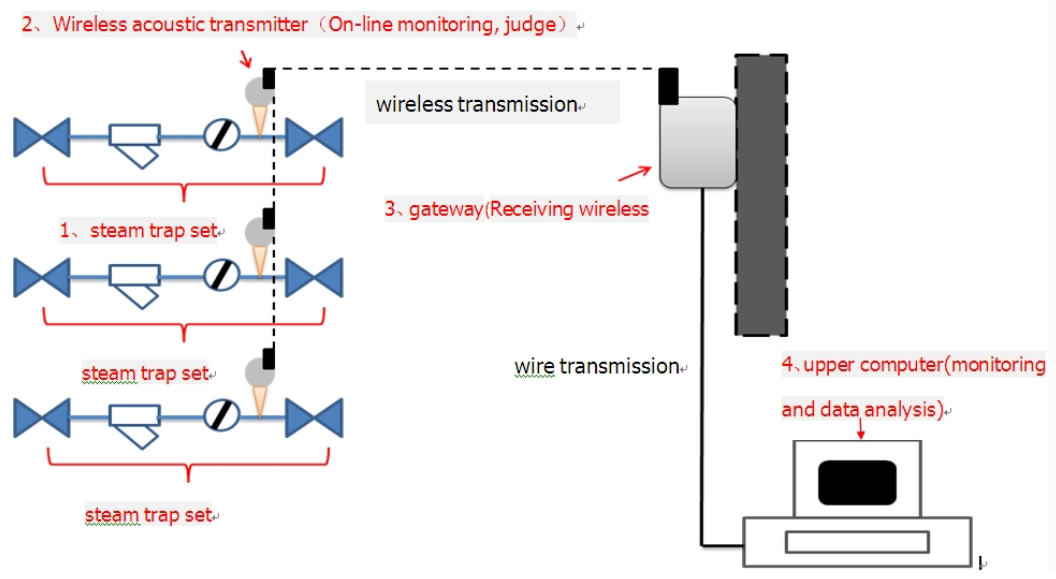

Figure 4 Monitoring system design sketch

\section{Monitoring system structure, function and application}

\section{Monitoring system composition}

Monitoring system consists of three parts: 1, Intelligent wireless networks composed by on-line monitoring instrument of trap. Each targeted trap is connected to a on-line monitoring instrument, and these instruments connect to each other, building up a self-organized wireless network. 2, Wireless gateway. Wireless gateway is to provide network access to wireless network equipment, and is responsible for the management of the whole wireless networks. 3, Automatic monitoring software platform. The basis of platform is trap-monitor specialized software containing the database system, and monitoring software communicates with wireless gateway through Ethernet, as shown in figure 5.

Monitoring system function

a) Online monitoring instrument is installed on the horizontal section of traps upstream within 15 $\mathrm{cm}$, and the probe is fixed to external pipe wall through the fixed hoop, and wireless instrument adopt the built-in antenna, which make installation and maintenance convenient. the probe has two built-in sensors, thermocouple sensor and ultrasonic sensors. When steam quickly flow from the high-pressure to the low-pressure through the micropore and cracks, near which turbulence come into being. The turbulence's flowing space is full of innumerable vortex of different sizes and shapes, which constantly generate, develop and rupture, thus ultrasonic is generated, which is little when condensed water emission normally. The existence of condensate water and its amount has effect on the pipe temperature, and instrument sent the measured signal of the ultrasonic wave and temperature to the monitoring software for data processing.

b) wireless gateway are responsible for the management of the wireless network. if increase wireless instrument in wireless network, just need to set network identity and add password of wireless gateway in the instrument. The Wireless gateway communicates with the monitoring software through Ethernet.

c) configuration parameters of monitoring software is set ,according to the different targeted trap ,including the type, the inlet pressure of trap, the back pressure of trap and the environment of trap, then synthesize parameters measured by instruments such as ultrasound and temperature of the targeted trap, under the support of system database, and obtain the work condition's calculation, analysis and judgments. Though this monitoring software, the information such as each targeted trap's 
geographical location, in which workshop, in which production lines, on which equipment and installation or the latest maintenance time is documented, thus installation and supervision of the trap really come ture.

\section{Monitoring system application}

The trap in the steam piping network of tobacco primary processing workshop in a cigarette factory in Hangzhou area is selected out for practical application, in order to make the effect more authenticity, A set of trap of produce steam and air conditioning steam for tobacco processing is selected out to compare, and the trap is tested under three kinds of states, normal, full of water (cooling) and steam leak.

(a)The trap's monitoring data under normal condition

When steam trap is in normal state, The temperature and vibration value is collected though on-line monitoring system in 30 minutes, and the data is as follows:

\begin{tabular}{|c|c|c|}
\hline \multicolumn{3}{|c|}{ outlet tenperature } \\
\hline tine & Silk production stean & Stean silk air conditioning \\
\hline $2015.6 .10 .14: 02$ & 97.61 & 89.28 \\
\hline $2015.6 .10 .14: 03$ & 97.88 & 90.07 \\
\hline $2015.6 .10 .14: 04$ & 97.31 & 91.17 \\
\hline $2015.6 .10 .14: 05$ & 97.98 & 91.13 \\
\hline $2015.6 .10 .14: 06$ & 97.52 & 91.00 \\
\hline $2015.6 .10 .14: 07$ & 97.68 & 90.71 \\
\hline $2015.6 .10 .14: 08$ & 98.05 & 89.38 \\
\hline $2015.6 .10 .14: 09$ & 97.66 & 89.25 \\
\hline $2015.6 .10 .14: 10$ & 97.74 & 89.20 \\
\hline $2015.6 .10 .14: 11$ & 98.48 & 89.27 \\
\hline $2015.6 .10 .14: 12$ & 98.61 & 89.41 \\
\hline $2015.6 .10 .14: 13$ & 97.82 & 89.21 \\
\hline $2015.6 .10 .14: 14$ & 97.63 & 88.96 \\
\hline $2015.6 .10 .14: 15$ & 98.53 & 89.35 \\
\hline $2015.6 .10 .14: 16$ & 97.82 & 88.35 \\
\hline $2015.6 .10 .14: 17$ & 98.65 & 88.41 \\
\hline $2015.6 .10 .14: 18$ & 98.62 & 88.54 \\
\hline $2015.6 .10 .14: 19$ & 97.63 & 88.64 \\
\hline $2015.6 .10 .14: 20$ & 97.21 & 88.74 \\
\hline $2015.6 .10 .14: 21$ & 98.81 & 88.69 \\
\hline $2015.6 .10 .14: 22$ & 97.88 & 88.69 \\
\hline $2015.6 .10 .14: 23$ & 98.43 & 89.12 \\
\hline $2015.6 .10 .14: 24$ & 97.93 & 89.25 \\
\hline $2015.6 .10 .14: 25$ & 98.96 & 89.05 \\
\hline $2015.6 .10 .14: 26$ & 99.63 & 89.31 \\
\hline $2015.6 .10 .14: 27$ & 98.36 & 88.74 \\
\hline $2015.6 .10 .14: 28$ & 97.96 & 88.95 \\
\hline $2015.6 .10 .14: 29$ & 98.42 & 89.88 \\
\hline $2015.6 .10 .14: 30$ & 98.63 & \\
\hline $2015.6 .10 .14: 31$ & 97.56 & 97.89 \\
\hline $2015.6 .10 .14: 32$ & 97.84 & \\
\hline & & \\
\hline
\end{tabular}

\begin{tabular}{|c|c|c|}
\hline \multicolumn{3}{|c|}{ Export vibration value } \\
\hline tine & Silk production stean & Stean silk air conditioning \\
\hline $2015.6 .10 .14: 02$ & 48.00 & 25.00 \\
\hline $2015.6 .10 .14: 03$ & 58.00 & 30.00 \\
\hline $2015.6 .10 .14: 04$ & 50.00 & 25.00 \\
\hline $2015.6 .10 .14: 05$ & 33.00 & 16.00 \\
\hline $2015.6 .10 .14: 06$ & 40.00 & 19.00 \\
\hline $2015.6 .10 .14: 07$ & 36.00 & 32.00 \\
\hline $2015.6 .10 .14: 08$ & 40.00 & 32.00 \\
\hline $2015.6 .10 .14: 09$ & 45.00 & 31.00 \\
\hline $2015.6 .10 .14: 10$ & 40.00 & 24.00 \\
\hline $2015.6 .10 .14: 11$ & 38.00 & 35.00 \\
\hline $2015.6 .10 .14: 12$ & 42.00 & 28.00 \\
\hline $2015.6 .10 .14: 13$ & 46.00 & 30.00 \\
\hline $2015.6 \cdot 10.14: 14$ & 39.00 & 28.00 \\
\hline $2015.6 .10 .14: 15$ & 43.00 & 33.00 \\
\hline $2015.6 .10 .14: 16$ & 36.00 & 26.00 \\
\hline $2015.6 .10 .14: 17$ & 40.00 & 35.00 \\
\hline $2015.6 .10 .14: 18$ & 40.00 & 24.00 \\
\hline $2015.6 .10 .14: 19$ & 45.00 & 30.00 \\
\hline $2015.6 .10 .14: 20$ & 37.00 & 27.00 \\
\hline $2015.6 .10 .14: 21$ & 46.00 & 32.00 \\
\hline $2015.6 .10 .14: 22$ & 40.00 & 25.00 \\
\hline $2015.6 .10 .14: 23$ & 48.00 & 30.00 \\
\hline $2015.6 .10 .14: 24$ & 42.00 & 21.00 \\
\hline $2015.6 .10 .14: 25$ & 47.00 & 31.00 \\
\hline $2015.6 .10 .14: 26$ & 40.00 & 25.00 \\
\hline $2015.6 .10 .14: 27$ & 46.00 & 36.00 \\
\hline $2015.6 .10 .14: 28$ & 40.00 & 27.00 \\
\hline $2015.6 .10 .14: 29$ & 45.00 & 33.00 \\
\hline $2015.6 .10 .14: 30$ & 36.00 & 22.00 \\
\hline $2015.6 .10 .14: 31$ & 43.00 & 30.00 \\
\hline $2015.6 .10 .14: 32$ & 39.00 & 24.00 \\
\hline & & \\
\hline & & \\
\hline
\end{tabular}

The outlet temperature of the steam trap in above picture just is outlet condensate temperature, and the temperature of condensate water the plant recycle for tobacco processing is hotter than the air conditioning steam's temperature, and lower than $110{ }^{\circ} \mathrm{C}$;

The outlet vibration value of trap in above picture refers to ultrasonic value produced in the process of discharging the condensate, under the normal state the value levels off, less than 100 counts;

The temperature, vibration value of trap under the normal state is displayed in curve, as shown in figure 6 , shown in figure 7 .

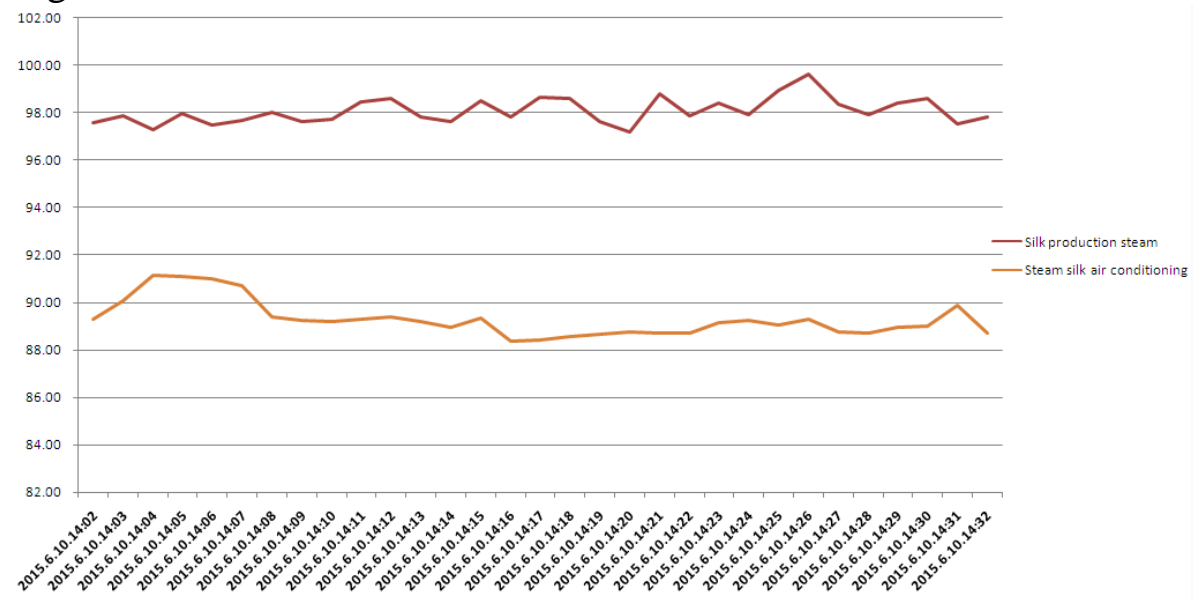

Figure 6 Curve of the drain valve under normal temperature 


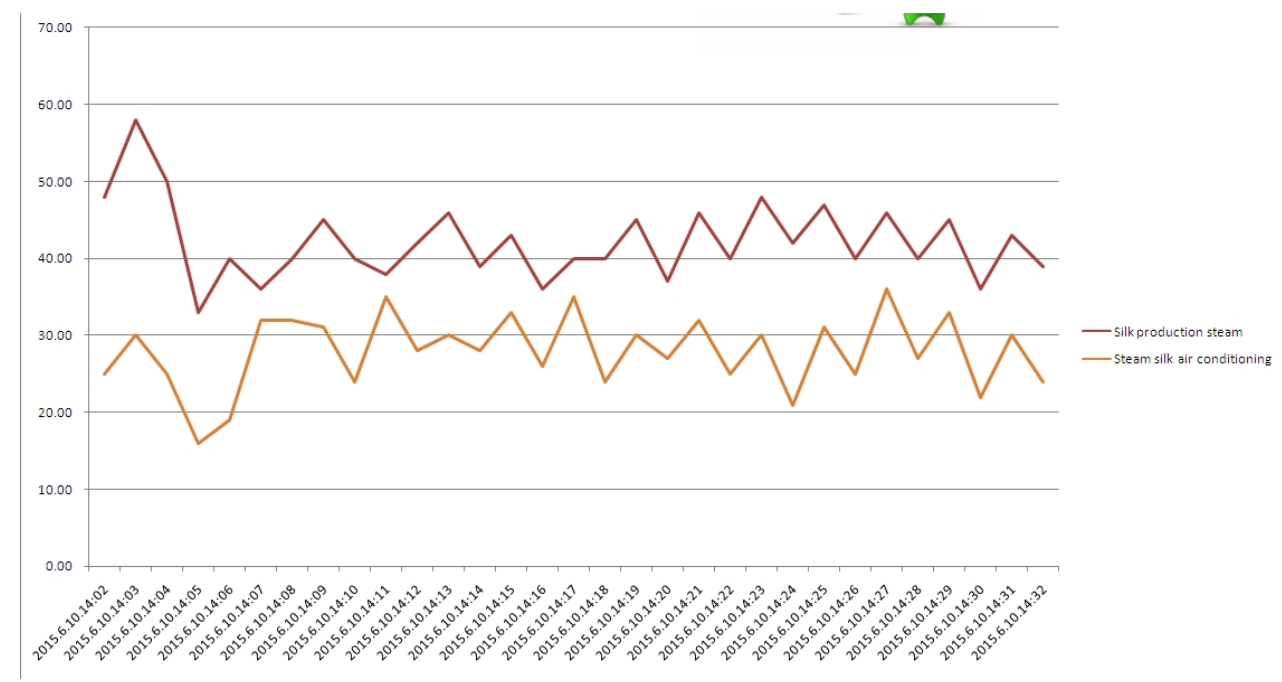

Figure 7 Vibration value curve of normal trap

By the data above, we can judge two set of traps for produce steam and air conditioning steam for tobacco processing work in a normal state, at this time the monitoring systems interface is shown in figure 8 .

\begin{tabular}{|c|c|c|c|c|c|c|c|c|}
\hline A & PaT & 目 & 708_ZS1_262 & 1 & 4 & - & wihartan & \\
\hline$\varphi$ & $P A T$ & 田 & 708_ZSS_261 & 1 & 4 & 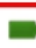 & wihartgx & \\
\hline 4 & $P A T$ & 目 & 708 ZKK__699 & 1 & 4 & = & wihart & Cold Trap \\
\hline 4 & $P$ : T & च & 708_JK1_270 & 1 & 4 & 둘 & wihartgx & \\
\hline 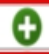 & $\mathrm{PaT}$ & v & 708_ZK1_264 & 1 & † & E & wihartgo & Blow Thru Trap/Bad Monitor Statu \\
\hline 4 & P\& & v & 708 ZZ1N_267 & 1 & $\boldsymbol{\epsilon}$ & $\bar{E}$ & wihartgr & \\
\hline
\end{tabular}

Figure 8 Monitoring results of system under normal condition

Monitoring data of trap in the condition full of water (cooling)

During in the period that plant shutdown for overhaul, temperature and vibration value in 30 minutes is collected by on-line monitoring system, and the data is shown below:

\begin{tabular}{|c|c|c|}
\hline \multicolumn{3}{|c|}{ outlet tepperature } \\
\hline tine & Silk production stean & Stean silk air conditioning \\
\hline $2015.2 .20 .10: 17$ & 16.81 & 12.61 \\
\hline 2015.2.20.10:18 & 17.12 & 12.46 \\
\hline 2015.2.20.10:19 & 16.61 & 12.05 \\
\hline 2015.2.20.10:20 & 16.45 & 12.25 \\
\hline 2015.2.20.10:21 & 16.96 & 12.45 \\
\hline 2015.2.20.10:22 & 16.35 & 12.55 \\
\hline 2015.2.20.10:23 & 16.75 & 11.94 \\
\hline 2015.2.20.10:24 & 16.60 & 12.08 \\
\hline 2015.2.20.10:25 & 16.65 & 12.08 \\
\hline 2015.2.20.10:26 & 16.36 & 12.11 \\
\hline 2015.2.20.10:27 & 16.21 & 12.32 \\
\hline 2015.2.20.10:28 & 16.53 & 12.25 \\
\hline 2015.2.20.10:29 & 16.93 & 12.24 \\
\hline 2015.2.20.10:30 & 15.68 & 12.63 \\
\hline 2015.2.20.10:31 & 15.63 & 12.25 \\
\hline 2015.2.20.10:32 & 16.58 & 11.99 \\
\hline 2015.2.20.10:33 & 15.74 & 12.03 \\
\hline 2015.2.20.10:34 & 15.93 & 12.14 \\
\hline 2015.2.20.10:35 & 15.34 & 12.22 \\
\hline $2015.2 .20 .10: 36$ & 16.41 & 12.33 \\
\hline 2015.2. 20.10:37 & 16.83 & 12.14 \\
\hline 2015.2.20.10:38 & 16.20 & 12.88 \\
\hline $2015.2 .20 .10: 39$ & 15.99 & 11.90 \\
\hline $2015.2 .20 .10: 40$ & 16.00 & 12.19 \\
\hline $2015.2 \cdot 20.10: 41$ & 16.51 & 12.18 \\
\hline $2015.2 \cdot 20 \cdot 10: 42$ & 16.87 & 12.36 \\
\hline $2015.2 .20 .10: 43$ & 15.88 & 12.50 \\
\hline 2015. 2. 20.10:44 & 15.42 & 12.64 \\
\hline $2015.2 .20 .10: 45$ & 16.35 & 12.45 \\
\hline $2015.2 .20 .10: 46$ & 16.36 & 12.36 \\
\hline $2015.2 .20 .10: 47$ & 16.84 & 12.54 \\
\hline
\end{tabular}

\begin{tabular}{|c|c|c|}
\hline \multicolumn{3}{|c|}{ outlet tepperature } \\
\hline tine & Silk production stean & Stean silk air conditioning \\
\hline $2015.2 .20 .10: 17$ & 16.81 & 12.61 \\
\hline $2015.2 .20 .10: 18$ & 17.12 & 12.46 \\
\hline $2015.2 .20 .10: 19$ & 16.61 & 12.05 \\
\hline $2015.2 .20 .10: 20$ & 16.45 & 12.25 \\
\hline $2015.2 .20 .10: 21$ & 16.96 & 12.45 \\
\hline $2015.2 .20 .10: 22$ & 16. 35 & 12.55 \\
\hline $2015.2 .20 .10: 23$ & 16.75 & 11.94 \\
\hline $2015.2 .20 .10: 24$ & 16.60 & 12.08 \\
\hline $2015.2 .20 .10: 25$ & 16.65 & 12.08 \\
\hline $2015.2 .20 .10: 26$ & 16.36 & 12.11 \\
\hline $2015.2 .20 .10: 27$ & 16.21 & 12.32 \\
\hline $2015.2 .20 .10: 28$ & 16.53 & 12.25 \\
\hline $2015.2 .20 .10: 29$ & 16.93 & 12.24 \\
\hline $2015.2 .20 .10: 30$ & 15.68 & 12.63 \\
\hline $2015.2 .20 .10: 31$ & 15.63 & 12.25 \\
\hline $2015.2 .20 .10: 32$ & 16.58 & 11.99 \\
\hline $2015.2 .20 .10: 33$ & 15.74 & 12.03 \\
\hline $2015.2 .20 .10: 34$ & 15.93 & 12.14 \\
\hline $2015.2 .20 .10: 35$ & 15.34 & 12.22 \\
\hline $2015.2 .20 .10: 36$ & 16.41 & 12.33 \\
\hline $2015.2 .20 .10: 37$ & 16.83 & 12.14 \\
\hline $2015.2 .20 .10: 38$ & 16.20 & 12.88 \\
\hline $2015.2 .20 .10: 39$ & 15.99 & 11.90 \\
\hline $2015.2 .20 .10: 40$ & 16.00 & 12.19 \\
\hline $2015.2 .20 .10: 41$ & 16.51 & 12.18 \\
\hline $2015.2 .20 .10: 42$ & 16.87 & 12.36 \\
\hline $2015.2 .20 .10: 43$ & 15.88 & 12.50 \\
\hline $2015.2 .20 .10: 44$ & 15.42 & 12.64 \\
\hline $2015.2 .20 .10: 45$ & 16.35 & 12.45 \\
\hline $2015.2 .20 .10: 46$ & 16.36 & 12.36 \\
\hline 2015.2.20.10:47 & 16.84 & 12.54 \\
\hline
\end{tabular}

During the shutdown, the boiler stop steam supply, from the temperature data above it can be seen that the trap is in a process of slowly cooling, and from the vibration value data above it can be seen that trap is at a stop working state.

The temperature, vibration value of trap in the condition full of water (cooling) is displayed in curve, as shown in figure 9 , shown in figure 10. 


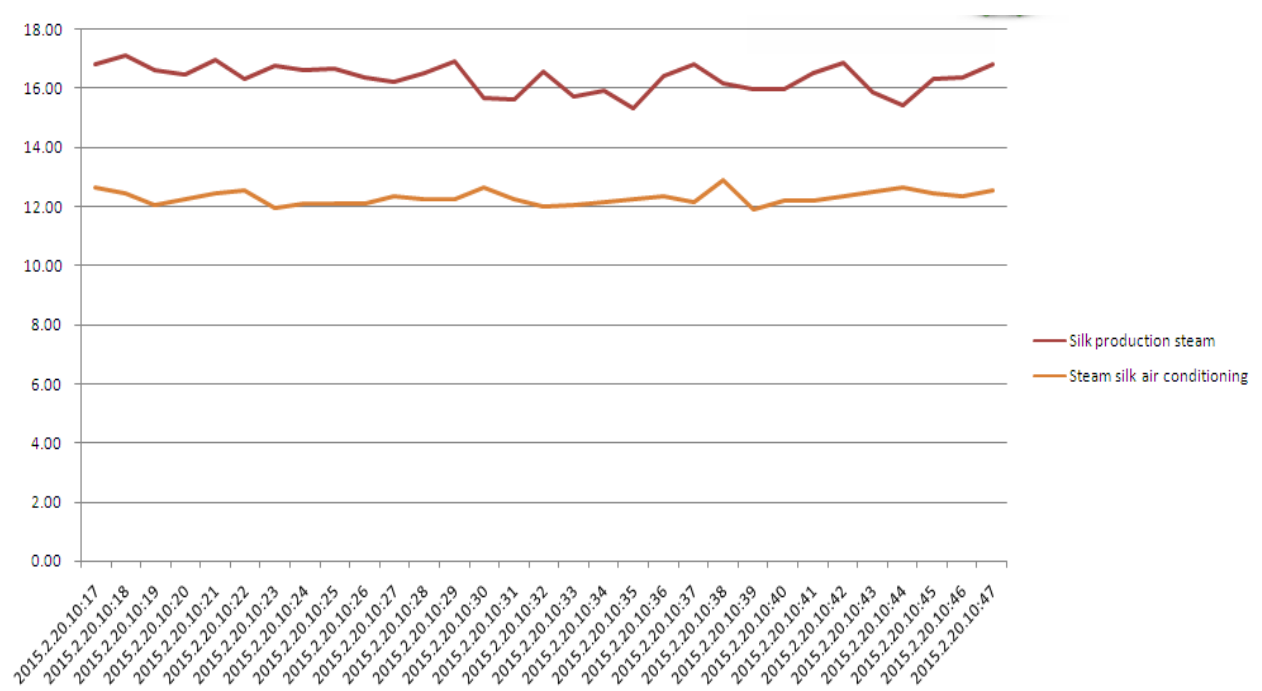

Figure 9 Temperature curve of steam trap in the condition full of water (cooling)

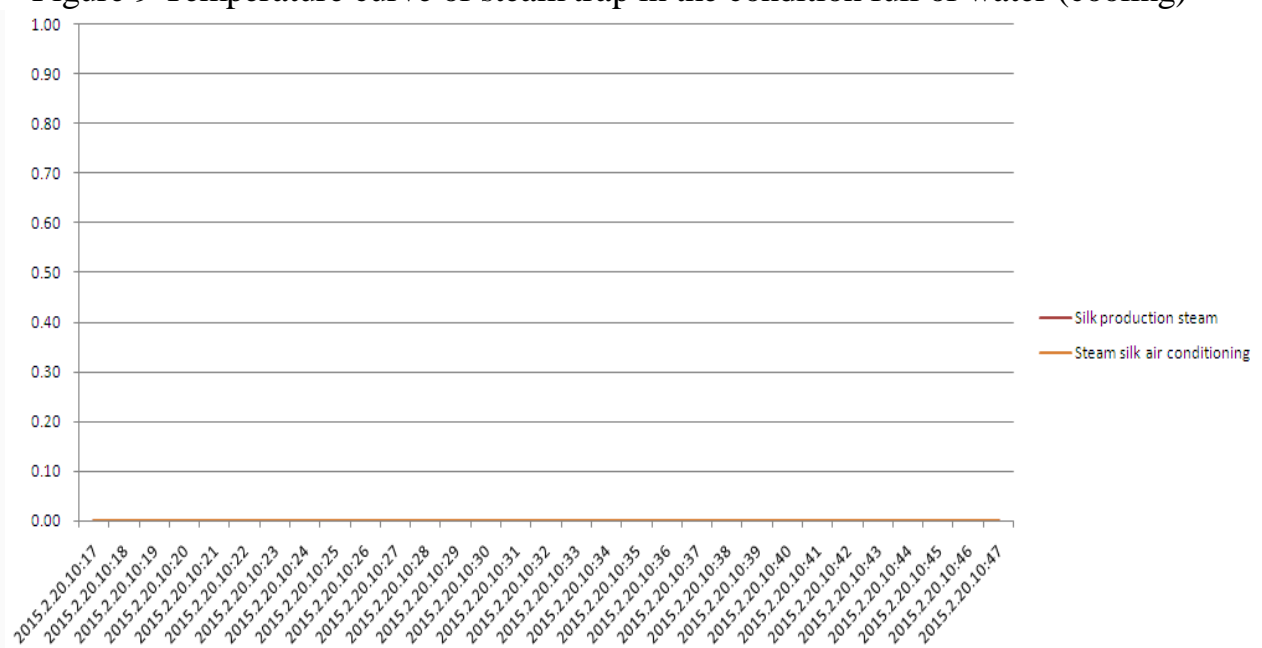

Figure 10 Vibration value curve of trap in the condition full of water (cooling)

By the data above, we can judge two set of traps for produce steam and air conditioning steam for tobacco processing stops drain water and is full of condensation water which also is known as full water state ,at this time the monitoring systems interface is shown in figure 11

\begin{tabular}{|c|c|c|c|c|c|c|c|}
\hline 웅 & $P \& T$ & 目 & 708_ZS1_262 & 1 & † & $\square$ & \multirow{2}{*}{ Good Trap/Good llonitor Status } \\
\hline 2 & $P \& T$ & ( v & 708_ZS3_261 & 1 & $\oplus$ & - & \\
\hline 웅 & $P \& T$ & 目 & 708_ZK3_269 & 1 & $\oplus$ & $\mathbf{0}$ & \multirow{4}{*}{ Cold Trap } \\
\hline 웅 & $P \& T$ & 目 & 708_JK1_270 & 1 & 4) & ㅁ & \\
\hline 2 & $P \& T$ & 目 & 708_ZK1_264 & 1 & $\oplus$ & $\mathbf{0}$ & \\
\hline 6 & $\mathrm{~F} \& \mathrm{~T}$ & 可 & 708_2K1_267 & 1 & 4 & D & \\
\hline
\end{tabular}

Figure 11 Monitoring results of system under the condition full of water (cooling)

monitoring data of trap in steam-leak condition

When steam trap is in steam-leak condition, The temperature and vibration value in 30 minutes is collected though on-line monitoring system, and the data is as follows: 


\begin{tabular}{|c|c|c|}
\hline \multicolumn{3}{|c|}{ outlet tenperature } \\
\hline tine & Silk production stean & Stean silk air conditioning \\
\hline $2015.9 .25 .14: 00$ & 94.50 & 101.84 \\
\hline $2015.9 .25 .14: 01$ & 94.27 & 103.10 \\
\hline $2015.9 .25 .14: 02$ & 95.95 & 102.62 \\
\hline $2015.9 .25 .14: 03$ & 97.17 & 103.00 \\
\hline $2015.9 .25 .14: 04$ & 95.71 & 102.91 \\
\hline $2015.9 .25 .14: 05$ & 96.67 & 103.39 \\
\hline $2015.9 .25 .14: 06$ & 94.57 & 103.05 \\
\hline $2015.9 .25 .14: 07$ & 95.75 & 102.91 \\
\hline $2015.9 .255 .14: 08$ & 96.15 & 108.17 \\
\hline $2015.9 .25 .14: 09$ & 97.48 & 109.76 \\
\hline $2015.9 .25 .14: 10$ & 97.92 & 110.54 \\
\hline $2015.9 .25 .14: 11$ & 98.53 & 111.38 \\
\hline $2015.9 .25 .14: 12$ & 98.81 & 111.76 \\
\hline $2015.9 .255 .14: 13$ & 98.87 & 111.53 \\
\hline 2015.9 .25 .1414 & 99.52 & 111.92 \\
\hline $2015.9 .25 .14: 15$ & 98.79 & 111.81 \\
\hline $2015.9 .25 .14: 16$ & 99.59 & 112.50 \\
\hline $2015.9 .25 .14: 17$ & 99.78 & 110.94 \\
\hline $2015.9 .25 .14: 18$ & 99.95 & 110.90 \\
\hline 2015.9 .25 .1419 & 99.58 & 111.40 \\
\hline $2015.9 .25 .14: 20$ & 98.65 & 113.41 \\
\hline $2015.9 .25 .14: 21$ & 97.85 & 122.08 \\
\hline $2015.9 .25 .14: 22$ & 96.58 & 122.24 \\
\hline $2015.9 .25 .14: 23$ & 97.89 & 122.55 \\
\hline $2015.9 .25 .14: 24$ & 98.92 & 123.21 \\
\hline $2015.9 .25 .14: 25$ & 99.53 & 120.25 \\
\hline $2015.9 .25 .14: 26$ & 97.21 & 126.42 \\
\hline $2015.9 .25 .14: 27$ & 99.62 & 123.25 \\
\hline $2015.9 .25 .14: 28$ & 98.96 & 122.58 \\
\hline $2015.9 .25 .14: 29$ & 98.11 & 123.21 \\
\hline $2015.9 .25 .14: 30$ & 97.85 & 122.89 \\
\hline
\end{tabular}

\begin{tabular}{|c|c|c|}
\hline \multicolumn{3}{|c|}{ Export vibration value } \\
\hline tine & Silk production stean & Stean silk air conditioning \\
\hline $2015.9 .25 .14: 00$ & 48.00 & 207.00 \\
\hline $2015.9 .25 .14: 01$ & 58.00 & 211.00 \\
\hline $2015.925 .414: 02$ & 50.00 & 197.00 \\
\hline $2015.9 .25 .14: 03$ & 33.00 & 234.00 \\
\hline $2015.9 .25 .14: 04$ & 40.00 & 201.00 \\
\hline $2015.9 .25 .14: 05$ & 36.00 & 201.00 \\
\hline $2015.9 .25 .14: 06$ & 40.00 & 225.00 \\
\hline $2015.9 .25 .14: 07$ & 45.00 & 197.00 \\
\hline $2015.9 .25 .14: 08$ & 40.00 & 201.00 \\
\hline $2015.925 .14: 09$ & 45.00 & 200.00 \\
\hline $2015.9 .25 .14: 10$ & 39.00 & 207.00 \\
\hline $2015.9 .25 .14: 11$ & 46.00 & 234.00 \\
\hline $2015.9 .25 .14: 12$ & 37.00 & 187.00 \\
\hline $2015.9 .25 .14: 13$ & 45.00 & 201.00 \\
\hline $2015.9 .25 .14: 14$ & 40.00 & 237.00 \\
\hline $2015.9 .25 .14: 15$ & 48.00 & 201.00 \\
\hline $2015.9 .25 .14: 16$ & 37.00 & 192.00 \\
\hline $2015.9 .25 .14: 17$ & 46.00 & 214.00 \\
\hline $2015.9 .25 .14: 18$ & 39.00 & 194.00 \\
\hline $2015.9 .25 .14: 19$ & 50.00 & 194.00 \\
\hline $2015.9 .25 .14: 20$ & 41.00 & 201.00 \\
\hline $2015.9 .25 .14: 21$ & 48.00 & 240.00 \\
\hline $2015.925 .414: 22$ & 37.00 & 210.00 \\
\hline $2015.9 .25 .14: 23$ & 49.00 & 255.00 \\
\hline $2015.9 .25 .14: 24$ & 40.00 & 255.00 \\
\hline $2015.9 .25 .14: 25$ & 45.00 & 201.00 \\
\hline $2015.9 .25 .14: 26$ & 41.00 & 240.00 \\
\hline $2015.9 .25 .14: 27$ & 48.00 & 240.00 \\
\hline $2015.9 .25 .14: 28$ & 38.00 & 234.00 \\
\hline $2015.925 .14: 29$ & 49.00 & 255.00 \\
\hline $2015.9 .25 .14: 30$ & 42.00 & \\
\hline & & \\
\hline
\end{tabular}

From the picture above, the outlet temperature of steam trap in air conditioning for tobacco processing was unexpectedly higher than normal value, and is far higher outlet temperature of produce steam for tobacco processing. Through the vibration value data, when the temperature begins to rise, the vibration value also rises obviously, which is higher than normal value and always at a high value.

The temperature, vibration value of trap in the condition full of water (cooling) is displayed in curve, as shown in figure 12, shown in figure13.

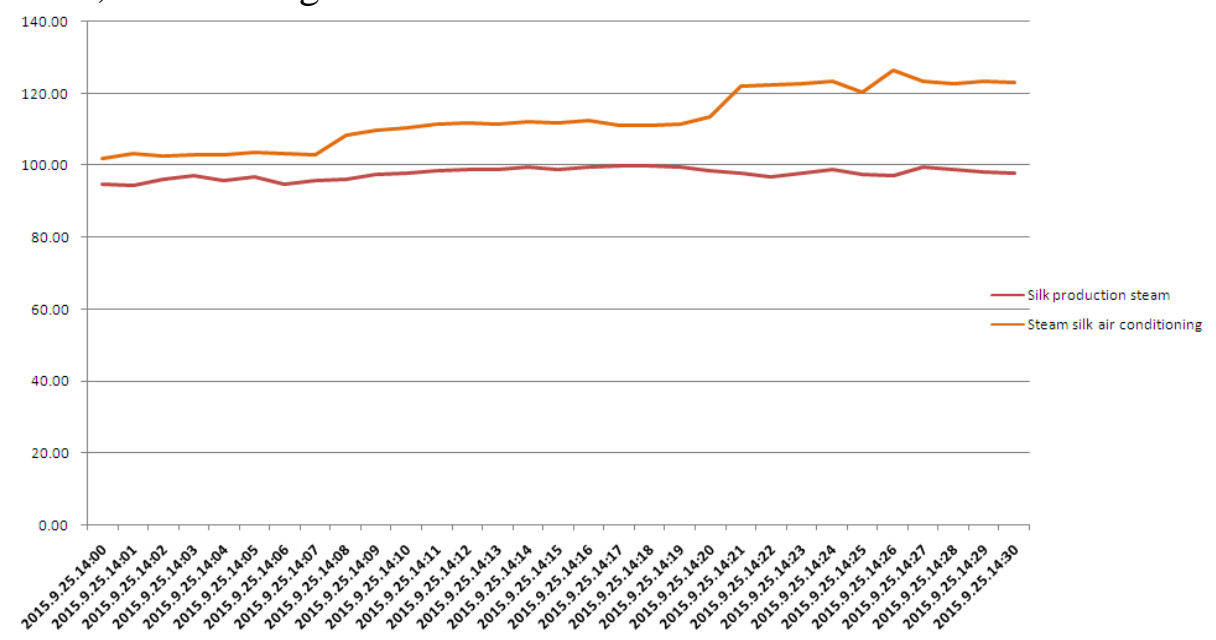

Figure 12 Temperature curve of trap in leaking condition

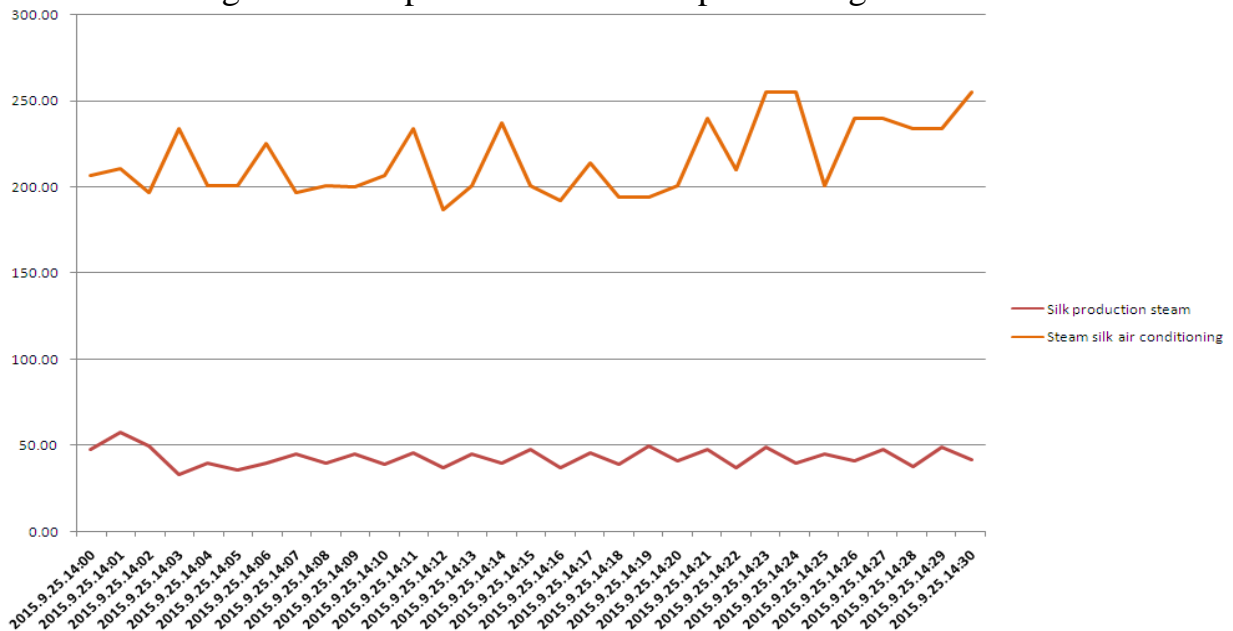

Figure 13 Vibration value curve of trap in leaking condition 
By the data above, it is known that the trap in air conditioning for tobacco processing is in steam-leak condition, and lots of steam flow quickly though the leak crack, which causes the turbulence and constantly produce continuous ultrasonic, and because of a large leakage, the outlet temperature of steam trap rises abnormally. , at this time the monitoring systems interface is shown in figure 14 .

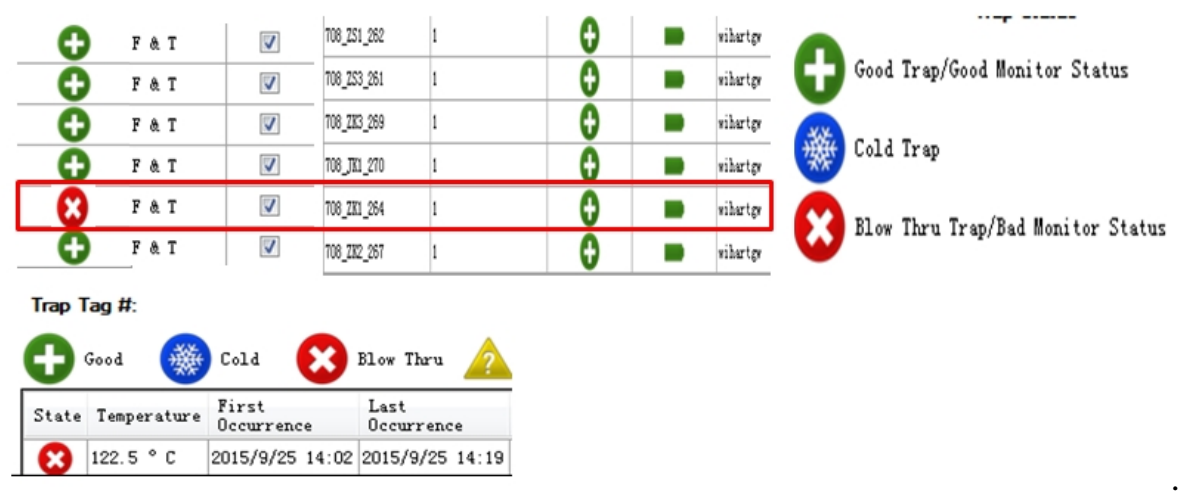

Figure 14 Monitoring results of system in steam-leak condition

\section{conclusion}

The practical application showed that the remote monitoring system of trap in steam pipe network solves the deficiency of accuracy and timeliness caused by traditional manual detection. Through the application of on-line remote monitoring system, the energy loss from the long-term steam leakage is effectively prevented, and destructive phenomenon- water hammer is effectively prevented, and the effective data and information is provided for steam system comprehensive performance evaluation.

\section{References}

[1] Pengyu.Recent Progressing of Wireless Communication under Industrial Environment and Application Potentialities in Energy-saving and Emission-reducing[J].CHINA INSTRUMENTATION.2008

[2] Wangyang.study and design of new leak-detect system based on Ultrasonic[DI]. Master degree thesis of Shanghai Jiao Tong University.2006

[3] Xie yongjun. Fault diagnosis and treatment of steam traps[j]. INNER MONGOLIA SCIENTECH AND ECONOMY. 2004. 